\title{
A Novel Approach to Water Plants using loT and Machine Learning
}

\author{
Moontasir Moon \\ Department of CSE \\ Daffodil International \\ University, Ashulia, \\ 1100,Bangladesh
}

\author{
Fariha Jahan \\ Department of CSE \\ Daffodil International \\ University, \\ Ashulia, \\ 1100,Bangladesh
}

\author{
Faraz Ahmed \\ Department of CSE \\ Daffodil International \\ University \\ Ashulia, \\ 1100,Bangladesh
}

\author{
Rakibul Hassan \\ Mokam LTD.-Cargo \\ Parcel \\ REDX Delivery \\ Dhaka, Bangladesh
}

\begin{abstract}
This paper describes an Internet of Things (IoT) based model that can automatically water the plants or lands when it needs water based on weather. Although many related works have been established on this topic, this proposed system would spontaneously water the plants or lands using groundwater when no reserved rainwater is available in the water tank. In the proposed model, a user connected to the internet would be able to control and monitor all the watering processes using a mobile application. The smart watering system uses solar energy to save electricity with a water pumping system. All the sensors, Arduino, Cloud, router, App, and its functionality have been adequately discussed in this paper. The sensor's data which is collected is processed by the control module and is sent to the cloud so that it can be retrieved in the user's mobile application. The proposed system can do all the tasks mechanically with the help of Machine learning, Big data, and IoT by taking permission from the user through the application. The result justifies the effectiveness of the proposed system.
\end{abstract}

\section{General Terms}

Machine Learning,Big Data,Internet of Things, Android application.

\section{Keywords}

Internet of Things (IoT) device, Big Data, Machine Learning, Arduino, Cloud, Sensors, Android application

\section{INTRODUCTION}

Water is an essential substance on earth. If there were no water, there would be no life since every single living being needs to must consume water to survive in this world. Apart from drinking water, there are many other uses for water such as keeping plants alive in gardens and parks, washing clothes, keeping houses clean, and cooking, etc. As everyday work depends on the water, therefore it is essential to learn and know how to save water and use it smartly. One of the primary sources of water is groundwater. For the increasing rate of population, the level of groundwater is decreasing day by day. The point plot shows that, on average, groundwater levels began to decrease in level between 2000-2010. The groundwater level sharply reduced. between 1990-2010. This is due to the high dependability on groundwater rather than its natural resources. In summary, as shown in Figure 2, the water level began to decrease in 1980-1995 gradually and continued decreasing sharply after that time. The total

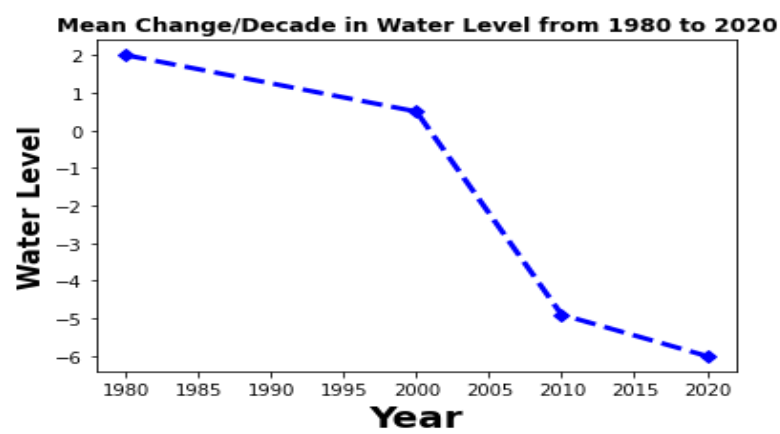

Fig 1: Change of Water Level

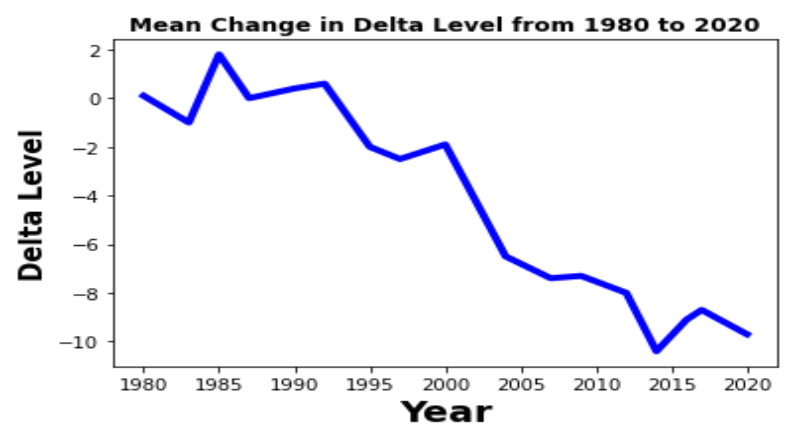

Fig 2: Change of Delta Level

decrease in water level from 1980 to 2020 was close to 10 in Colorado, USA. It is high time to save groundwater and use water from other sources as much as we can, like rainwater. IoT is a recent powerful technology capable of communicating and exchanging data between different machines and devices through the internet. IoT refers to those things that get used by the devices that connect with the internet and allows us to control and receive data from the computer or smartphone. The fact is, IoT is essential for both industrial and residential use. The Internet of Things saves peoples time, money, and provides an intelligent solution to a problem. This paper consists of a proposed model to collect and use rainwater. The paper also focuses on an intelligent solution with the help of Machine learning, Big data, Arduino, Solar, and some sensors. The rest of the paper is organized as follows. A literature review is presented in Section II and the methodology is described in detail in Section III. Results and discussions are discussed in Section IV. Future work is in Section V. Finally, Section VI concludes authors work. 


\section{LITERATURE REVIEW}

Researchers have proposed many different models to save water using IoT. Few related works have been explained below:

A technical document has been published in [13], designed an electronic system using Automatic Water Level Sensor, Controller System to monitor and control the tank's water level. The system could display and manage water in different Ten levels from zero to nine. Home and Industrial users could use the electronic system to control and monitor water. JK flip-flop and seven-segment display were also used in this proposed system. In [12] the proposed model for Measurements of Volume, Volumetric Flow, and Liquid Level of a tank by using two Ultrasonic Sensors. The model helped to assess the capacity of a tank. The ultrasonic sensor was used for controlling and measuring the contained liquid level. The second ultrasonic sensor was placed above the tank's mouth to measure the quantity of water. The approach automatically controlled and measured the liquid level, volume, and volumetric flow during emptying processes. [14] proposed a model which consists of a Water Monitoring System which was built on a microcontroller-based platform, Arduino Uno board, interfaced with an Ultrasonic sensor, and GSM modem. At the top, an ultrasonic sensor was placed to measure the stature of the Can. Two different sensors were used to make this model. These two sensors transferred data in between using integrating a wireless gateway within the consumer network. [1] proposed an IoT device that helped to plan and manage water usage. The sensor was placed in the tank, and it sent the updated information to the Cloud so that the users could get current updated information on water level using an application. The user could monitor the water level from anywhere if the smartphone was connected to the internet. This system would spontaneously turn on the pump when the water level was low and vice-versa. [7] proposed a water quality monitoring (WQM) model using wireless sensor network (WSN) technology. This model consists of sensors, a design board, a field-programmable gate array board, a personal computer, wireless communication module. The FPGA was programmed with VHDL. This proposed water quality management system collects five parameters: Water level, $\mathrm{pH}$ of water, Carbon dioxide, Turbidity, and the temperature of the water. These five parameters helped the intelligent system to measure the quality of water. [10] the paper was about automated water quality monitoring. Using some sensors, this model could automatically identify the quality of water. Raspberry pi was used as an embedded system. which would help the manufacture of detecting sensors devices, and remote communications technology also allowed the interaction of sending data. This model could operate as an automated water monitor Sensor, and it could monitor the quality of water. This intelligent system could monitor water quality using passive and active sensors.
Table 1: History of Related Research

\begin{tabular}{|c|c|c|}
\hline Author & Techniques & Benefits \\
\hline $\begin{array}{l}\text { Rizqiputrin } \\
\text { ourmabudi } \\
\text { arti et al. }\end{array}$ & $\begin{array}{l}\text { Automated water } \\
\text { quality } \\
\text { monitoring }\end{array}$ & $\begin{array}{l}\text { Identify the } \\
\text { quality of water } \\
\text { automatically. } \\
\text { Easy to } \\
\text { implement. }\end{array}$ \\
\hline $\begin{array}{l}\text { Cho zin } \\
\text { myint et al. }\end{array}$ & $\begin{array}{l}\text { Water quality } \\
\text { monitoring using } \\
\text { sensors. }\end{array}$ & $\begin{array}{l}\text { Easy to measure } \\
\text { the quality of } \\
\text { water. } \\
\text { The cost is very } \\
\text { low. }\end{array}$ \\
\hline $\begin{array}{l}\text { SayaliWad } \\
\text { ekar et al. }\end{array}$ & $\begin{array}{l}\text { Water } \\
\text { management } \\
\text { using IOT } \\
\text { devices. }\end{array}$ & $\begin{array}{l}\text { Automatically } \\
\text { Power off and on } \\
\text { the system. } \\
\text { Monitor the water } \\
\text { level from } \\
\text { anywhere. }\end{array}$ \\
\hline $\begin{array}{l}\text { Thinagaran } \\
\text { Perumal et } \\
\text { al. }\end{array}$ & $\begin{array}{l}\text { Water Monitoring } \\
\text { System GSM } \\
\text { modem and } \\
\text { Ultrasonic sensor }\end{array}$ & $\begin{array}{l}\text { Easy to build, and } \\
\text { the cost is also } \\
\text { very low. }\end{array}$ \\
\hline $\begin{array}{l}\text { Nicola } \\
\text { Ivan } \\
\text { Giannocc } \\
\text { aro and } \\
\text { Luigi } \\
\text { Spedicato }\end{array}$ & $\begin{array}{l}\text { Measure water } \\
\text { level using } \\
\text { ultrasonic sensor. }\end{array}$ & $\begin{array}{l}\text { It helps to save } \\
\text { tanks from } \\
\text { overflowing with } \\
\text { water. } \\
\text { Easy to install in } \\
\text { residential } \\
\text { societies. }\end{array}$ \\
\hline $\begin{array}{l}\text { BezaNegas } \\
\text { hGetu and } \\
\text { Hussain A. } \\
\text { Attia }\end{array}$ & $\begin{array}{l}\text { Tanks water } \\
\text { control and } \\
\text { monitor } \\
\text { automatically }\end{array}$ & $\begin{array}{l}\text { - Can identify the } \\
\text { water level in ten } \\
\text { different layers. } \\
\text { Easy to control } \\
\text { and monitor. }\end{array}$ \\
\hline
\end{tabular}

\section{RESEARCH METHOD}

The rainwater was collected in a tank, and that tank was connected with a SS water level sensor, which helped to monitor the water level of the tank. Four SS water level sensors were used. The user monitored the tank's water level using an app connected to the internet. 


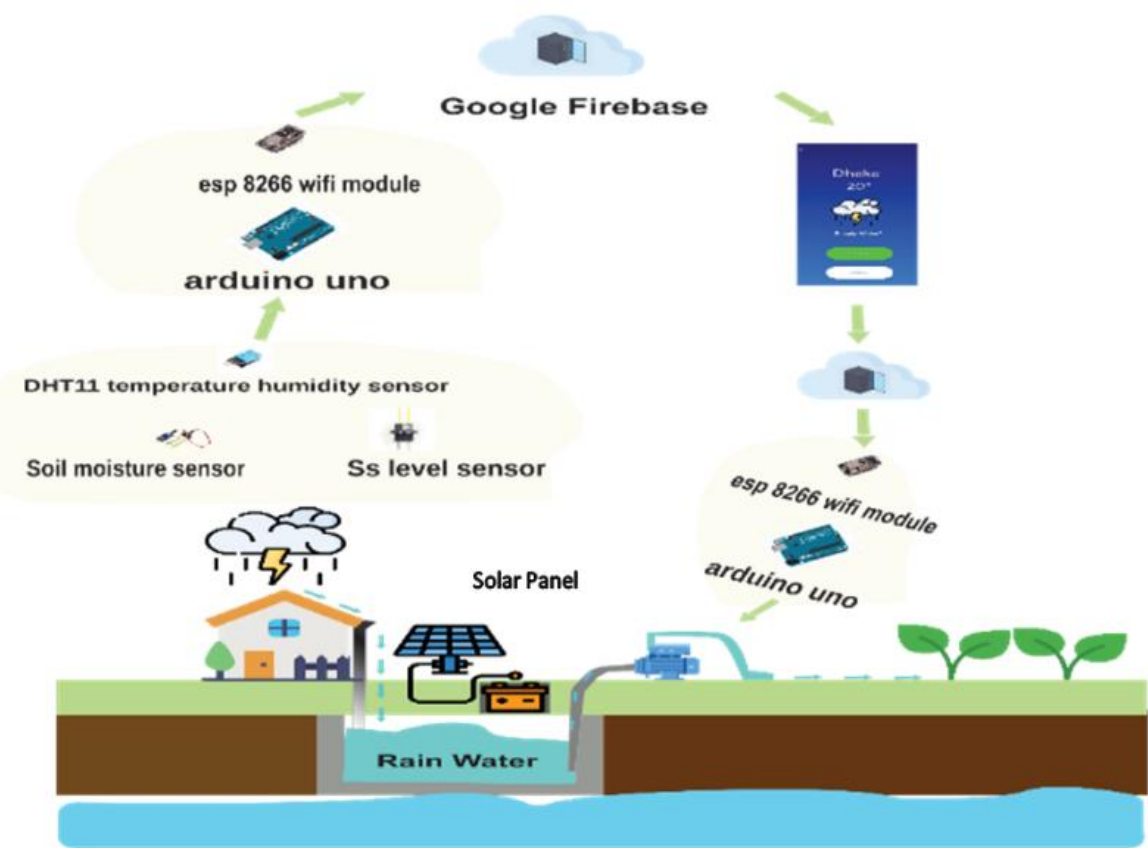

Fig 3.1: Proposed System's Diagram(with reserved rain water)

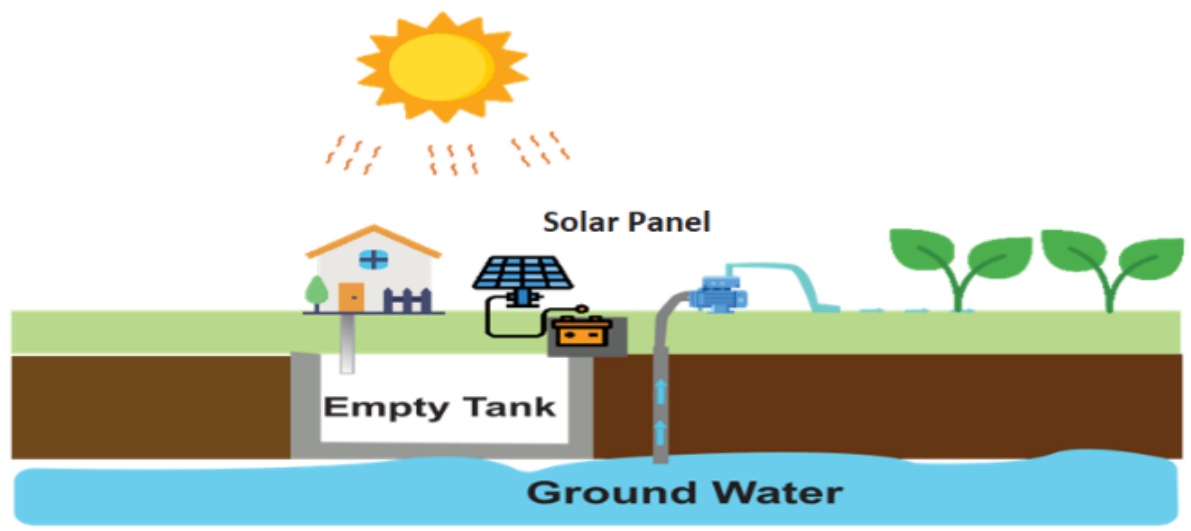

Fig 3.2: Proposed System's Diagram (with empty tank)

A soil moisture sensor was added with the soil or the soil of the tree. The sensor helped to know the water requirement from the soil or the tree. When the sensor identifies that the soil or tree needs water, it sends the data to Arduino. After getting the signal, Arduino started collecting all the necessary data by using all the sensors. The collected data then gets sent by the Arduino to Google's Firebase using the ESP8266 wi-fi module. After getting all the data, the weather condition (whether there is a possibility of rain that day or not) gets checked by the device. The required water amount gets measured by the system with the help of Big Data and Machine learning where there is any rain prediction from the weather. After the calculation, the reserved water tank gets measured by the system. If the tank has enough water, the user gets notified by the system that trees or land need water.If the user presses the Yes button, that means the user permits the system for watering the lands using the reserve tank [Fig: 3.1].The user also gets notified by the system about no reserved water in the tank. In that time user will permit to the system for watering the lands using groundwater[Fig: 3.2]. After that, the system permits to send data to google firebase to start the water system. The data gets send by Google's firebase database to the Arduino when to start the pump and when to stop. The user gets to decide when to stop the process by just clicking the "No" button on the App.Table 2 elaborates the algorithm for checking whether the tank is full or empty. Figure 4.1 illustrates the methodology.

Table 2: Algorithm for collecting water

Algorithm Checking water level inside the tank

if rain starts

checks if the tank is empty or full

if the tank is empty

collects water until the tank gets full

else the tank is full

stops the operation 


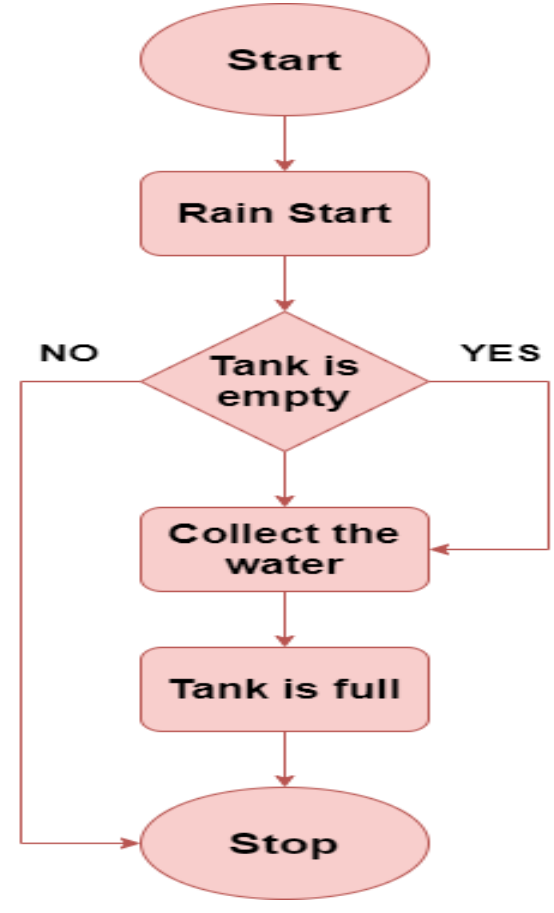

Fig 4.1: Flow Chart and Algorithm 1

Table 3 elaborates the algorithm for the complete water supply operation in general. Figure 4.2 illustrates the methodology.

Table 3: Algorithm for water supply process

\begin{tabular}{|l|}
\hline Algorithm Water supply and user command \\
Sensor X Checks the water level \\
if needed water \\
checks the weather \\
sends data to cloud server \\
calculates the required amount of water \\
moisture gets notified from the cloud \\
if user gives the command to water from tank \\
else user gives the command to water from ground \\
else terminates the process
\end{tabular}

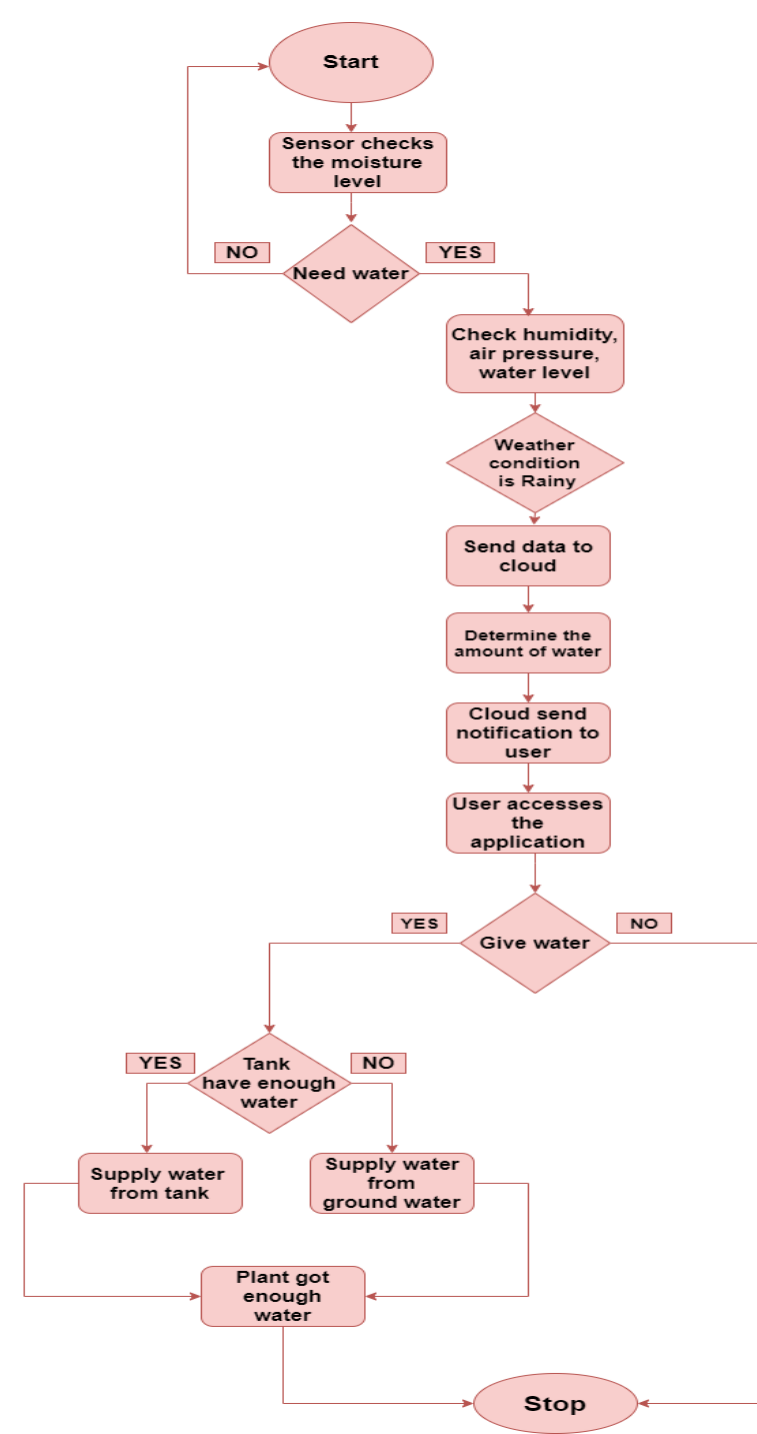

Figure 4.2: Flow Chart and Algorithm 2

Esp8266 wi-fi module: Esp8266 is a low-cost Serial-to wi-fi module. To communicate with the microcontroller, it uses a 9600 baud rate. It is a self-contained SoC that uses TCP/IP protocol to communicate to the webserver. It also comes preprogrammed, and using AT command, we can communicate to the firmware.

Arduino Uno: Arduino Uno is a microcontroller board. This is based on ATmega328P. It has a USB connection, 14 digital input/output pins, an ICSP header, a reset button, a power jack, and $16 \mathrm{MHz}$ ceramic resonators. We can easily connect it to thecomputer with the help of a USB cable. AC-to-DC adapter or battery can power it. We also can change its chip for a few dollars if it needs to change.

Soil Moisture Sensor: The soil moisture sensor is used to check volumetric water content. The calculated property and moisture of soil may be changed based on ecological factors like the type of soil, temperature, or otherwise electric conductivity. The soil moisture sensor has four pins VCC pin for power, A0 pin for analog output, D0 pin for digital output, GND pin for ground.

Ss Water Level Sensor: Here, ss stand for Stainless Steel. Stainless Steel water level sensor used to detect the height of water of the tank. This sensor can be used for any water level 
controller system. It works on the principle of magnets and magnetic switches. The process of installation of this sensor is also straightforward.

Dht11: DHT11 is a digital sensor of temperature and humidity. The weather station uses this sensor to measure atmospheric temperature and moisture. So that experts can make predictions of rain for the coming days. The cost of this sensor is meager. It is straightforward to use cars, Offices, industries, and greenhouses to use this sensor for measuring humidity values.

Solar Panel: The solar panel is a device that first absorbs the sun's rays, and then it converts the ray into heat. We use it to generate electricity. It is a collection of solar cells. There are three major types of solar panels thin-film, polycrystalline, and monocrystalline. We can use solar panels to remote power supply, battery charger, portable power supply, etc.

Machine Learning:Machine learning is a method that analyzes the data so that a system can learn from the data to make a decision. Machine learning is a branch of artificial intelligence. Without being explicitly programmed, a computer can perform tasks with the help of machine learning. There are three well-known methods to train machine learning algorithms: supervised learning, unsupervised learning, and reinforcement learning.

Big Data: A vast collection of data in size and growing fast with time is called big data, these three types of big data: Structured, unstructured, semi-structured. The process of big data brings multiple benefits to improve people's business, better operational efficiency, customer service, etc. The analytics of Big data helps us in the time of significant and better decisions.

Google Firebase: it is a Google-backed and powered application development software. Which enables developers to develop web apps, Android and iOS. It provides tools for tracking analytics, fixing reporting, and app crashes. Services of firebase are Cloud messaging, real-time database, Test lab, etc.

Barometer: A barometer is a scientific instrument that helps us to measure atmospheric pressure. It also helps to measure altitude. There are two kinds of barometers: Aneroid and Mercury.

\section{RESULTS AND DISCUSSION}

The system also gets monitored by the developed App. The level of water gets monitored by the users on the App. The App was built for a cross-platform environment (Android, IOS). A separate App was developed so that the user could easily monitor the level of water.
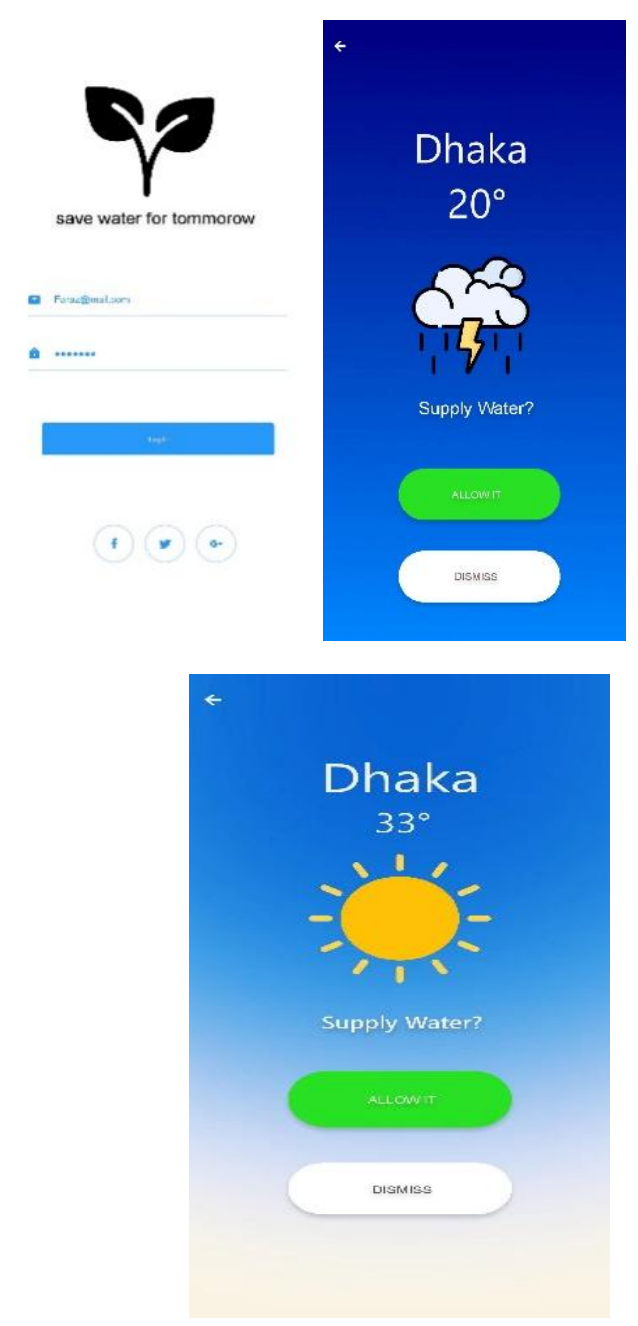

Fig 5:Prototype of the proposed Application

Table 4: Estimation of the entire project Cost

\begin{tabular}{|l|l|l|}
\hline Equipment & $\begin{array}{l}\text { Needed Quantity } \\
\text { per acre }\end{array}$ & Price(taka) \\
\hline Soil moisture & 1 & 100 \\
\hline $\begin{array}{l}\text { SS Water level } \\
\text { sensor }\end{array}$ & 4 & 2,000 \\
\hline $\begin{array}{l}\text { Solar water } \\
\text { pump }\end{array}$ & 2 & 10,400 \\
\hline Solarpanel & 1 & 22,500 \\
\hline DHT11 & 1 & 100 \\
\hline Arduino UNO & 1 & 750 \\
\hline $\begin{array}{l}\text { ESP8266 wi-fi } \\
\text { module }\end{array}$ & 1 & 200 \\
\hline
\end{tabular}




\begin{tabular}{|l|l|l|}
\hline $\begin{array}{l}\text { BMP180 } \\
\text { Barometric }\end{array}$ & 1 & 250 \\
\hline $\begin{array}{l}\text { Barometer } \\
\text { sensor }\end{array}$ & 1 & 250 \\
\hline Total & 36,550 \\
\hline
\end{tabular}

The table is showing that it is also possible to build the proposed system with a low budget.

\section{FUTURE WORK}

This paper parades many possibilities for future work. Some additional modeling and analysis tools could be applied to the current project. The mentioned development of this project was an important direction for future research. Further research to provide problem-dependent guidance. To reduce the cost of this project, more work could be done on this project. From this proposed paper practical implementation can be done and it is believed that it will inspire future researchers also. The system could be implemented both on a personal level and an agricultural level. In most countries, highly dependent agricultural areas lack a good water management system due to the decrease of groundwater level as mentioned in figure 1 and figure 2. That's why this system will be a cost-effective solution for a better water management system in these areas.

\section{CONCLUSION}

A novel intelligent water monitoring and supply system was presented. It allowed users to save the waste of groundwater, collecting the rainwater, and use the rainwater automatically when plants or land needed water. Thanks to the proposed innovative approach, the users can control and monitor all processing tasks using an application. The system encouraged the save of water and reuse of natural water sources in a costeffective manner.

\section{REFERENCES}

[1] Wadekar, S., Vakare, V., Prajapati, R., Yadav, S. and Yadav, V., 2016, October. Smart water management using IOT. In 2016 5th International Conference on Wireless Networks and Embedded Systems (WECON) (pp. 1-4). IEEE.

[2] Kamienski, C., Soininen, J.P., Taumberger, M., Dantas, R., Toscano, A., Salmon Cinotti, T., Filev Maia, R. and Torre Neto, A., 2019. Smart water management platform: IoT-based precision irrigation for agriculture. Sensors, 19(2), p.276.

[3] Suresh, M., Muthukumar, U. and Chandapillai, J., 2017, July. A novel smart water-meter based on IoT and smartphone app for city distribution management. In 2017 IEEE region 10 symposium (TENSYMP) (pp. 15). IEEE.

[4] Radhakrishnan, V. and Wu, W., 2018, June. IoT technology for smart water system. In 2018 IEEE 20th International Conference on High Performance Computing and Communications; IEEE 16th International Conference on Smart City; IEEE 4th International Conference on Data Science and Systems (HPCC/SmartCity/DSS) (pp. 1491-1496). IEEE.
[5] Bouwer, H., 2000. Integrated water management: emerging issues and challenges. Agricultural water management, 45(3), pp.217-228.

[6] Parashar, M., Patil, R., Singh, S., VedMohan, V. and Rekha, K.S., 2018. Water level monitoring system in water dispensers using IoT. International Research Journal of Engineering and Technology (IRJET), 5(04), pp.2395-0056.

[7] Myint, C.Z., Gopal, L. and Aung, Y.L., 2017, May. Reconfigurable smart water quality monitoring system in IoT environment. In 2017 IEEE/ACIS 16th international conference on computer and information science (ICIS) (pp. 435-440). IEEE.

[8] Encinas, C., Ruiz, E., Cortez, J. and Espinoza, A., 2017, April. Design and implementation of a distributed IoT system for the monitoring of water quality in aquaculture. In 2017 Wireless Telecommunications Symposium (WTS) (pp. 1-7). IEEE.

[9] Skarga-Bandurova, I., Krytska, Y., Shorokhov, M., Suvorin, O., Barbaruk, L. and Ozheredova, M., 2019, August. Towards development IoT-based water quality monitoring system. In 2019 7th International Conference on Future Internet of Things and Cloud Workshops (FiCloudW) (pp. 140-145). IEEE.

[10] Budiarti, R.P.N., Tjahjono, A., Hariadi, M. and Purnomo, M.H., 2019, October. Development of IoT for automated water quality monitoring system. In 2019 International Conference on Computer Science, Information Technology, and Electrical Engineering (ICOMITEE) (pp. 211-216). IEEE.

[11] Vijayakumar, N. and Ramya, A.R., 2015, March. The real time monitoring of water quality in IoT environment. In 2015 International Conference on Innovations in Information, Embedded and Communication Systems (ICIIECS) (pp. 1-5). IEEE.

[12] Giannoccaro, N.I. and Spedicato, L., 2012. Ultrasonic sensors for measurements of liquid level, volume and volumetric flow in a tank. Precision Instrument and Mechanology.

[13] Getu, B.N. and Attia, H.A., 2016, December. Automatic water level sensor and controller system. In 2016 th International Conference on Electronic Devices, Systems and Applications (ICEDSA) (pp. 1-4). IEEE.

[14] Westall F, Brack A. The importance of water for life. Space Science Reviews. 2018 Mar;214(2):1-23.

[15] Wen Y, Xu J. Scientific importance of water- processable PEDOT-PSS and preparation, challenge and new application in sensors of its film electrode: a review. Journal of Polymer Science Part A: Polymer Chemistry. 2017 Apr 1;55(7):1121-50.

[16] Kelly MR, Lant NJ, Kurr M, Burgess JG. Importance of water-volume on the release of microplastic fibers from

[17] laundry. Environmental science \& technology. 2019 Aug 28;53(20):11735-44.

[18] Mandal M, Huang G, Hassan NU, Peng X, Gu T, Brooks-Starks AH, Bahar B, Mustain WE, Kohl PA. The importance of water transport in high conductivity and high-power alkaline fuel cells. Journal of The Electrochemical Society. 2019 Oct 9;167(5):054501. 
[19] Cha Y, Cho KH, Lee H, Kang T, Kim JH. The relative importance of water temperature and residence time in predicting cyanobacteria abundance in regulated rivers. Water research. 2017 Nov 1;124:11-9.

[20] Sreekumar A, Punnathanam V, Shastri Y. Sustainability driven design of lignocellulosic ethanol system highlighting importance of water footprint. Biomass and Bioenergy. 2021 Aug 1;151:106174.

[21] Kiani H, Sun DW. Water crystallization and its importance to freezing of foods: A review. Trends in Food Science \& Technology. 2011 Aug 1;22(8):407-26. 